\title{
Developing Brains, Developing Nations: Can Scientists Be Effective Non-state Diplomats?
}

\author{
Giovanni A. Carosso ${ }^{1,2}$, Leonardo M. R. Ferreira ${ }^{1,3,4}$ and Mohammed A. Mostajo-Radji ${ }^{1,5,6 *}$ \\ ${ }^{1}$ Clubes de Ciencia Bolivia Foundation, Santa Cruz de la Sierra, Bolivia, ${ }^{2}$ Predoctoral Training Program in Human Genetics, \\ McKusick-Nathans Institute of Genetic Medicine, Johns Hopkins University School of Medicine, Baltimore, MD, \\ United States, ${ }^{3}$ Department of Surgery, University of California, San Francisco, San Francisco, CA, United States, ${ }^{4}$ Diabetes \\ Center and Sean N. Parker Autoimmune Research Laboratory, University of California, San Francisco, San Francisco, CA, \\ United States, ${ }^{5}$ Department of Neurology, University of California, San Francisco, San Francisco, CA, United States, ${ }^{6}$ The Eli \\ and Edythe Broad Center of Regeneration Medicine and Stem Cell Research, University of California, San Francisco, \\ San Francisco, CA, United States
}

Keywords: science education, Bolivia, United States, science diplomacy, STEM education and minorities

\section{INTRODUCTION}

\section{OPEN ACCESS}

Edited by:

Ida Ah Chee Mok,

The University of Hong Kong,

Hong Kong

Reviewed by:

Jon Mason

Charles Darwin University, Australia Angela DosAlmas,

Binghamton University, United States

*Correspondence:

Mohammed A. Mostajo-Radji mohammed@

clubesdecienciabolivia.com

Specialty section:

This article was submitted to

STEM Education,

a section of the journal

Frontiers in Education

Received: 16 May 2019

Accepted: 21 August 2019 Published: 03 September 2019

Citation:

Carosso GA, Ferreira LMR and Mostajo-Radji MA (2019) Developing Brains, Developing Nations: Can Scientists Be Effective Non-state Diplomats? Front. Educ. 4:95. doi: 10.3389/feduc.2019.00095
Foreign education efforts by institutions of developed nations often meet resistance abroad, when the need for national sovereignty stands in opposition to collaborative opportunities with outside states. Strict isolationist policies can not only impact diplomatic ties, but also prevent the transfer of technologies, knowledge, and innovation that ultimately drive economic strength. Developing nations are particularly vulnerable to stagnation-both economic and scientific-when divorced from the march of global progress. We believe there is a balance to be struck whereby advances can be shared to mutual benefit on all sides while respecting local contexts, and science education may serve as an effective vehicle for such cross-border connection.

In September 2008, the Bolivian government expelled the U.S. Ambassador amid diplomatic strains arising deep within the tropical province of Chapare, a major production zone of a long-held facet of Bolivian tradition-the coca leaf. U.S. efforts in the region were aimed at halting the diversion of coca for illicit uses, but in doing so ignited sharp sensitivities over a cultural staple used for millennia by indigenous peoples in medicinal and religious contexts. Today, the two countries still lack ambassadors, retaining only diplomatic missions under respective charges d'affaires (Birns and Sanchez, 2011). The split is emblematic of a larger gap in cross-border understanding, in a nation where a subset of vocal, nationalist attitudes has historically eschewed state-of-the-art science as strictly an instrument of global elitism. By bringing education in cutting-edge science, technology, engineering, and mathematics (STEM) to Bolivian youth, we've already begun to see a shift in public understandings that increasingly recognize the role of STEM as a driver of economic progress (Ferreira et al., 2019).

Bolivia sees the highest rates of poverty and social inequality in Latin America and the Caribbean (LAC), consistently ranking near last in a suite of economic indicators of innovation, technological expertise, skilled labor, and education. The country has the lowest university completion rate of all LAC nations, the largest disparity in educational attainment between rural and urban students, the greatest decline in wage premiums for university graduates, and is unique in having a school dropout rate higher than its completion rate. However, by 2030, economists project that Bolivia will be home to the top three fastest-growing Latin American cities. It is therefore critical that educational outcomes in Bolivia match the pace of economic expansion, if the country is to achieve competitive status on the global stage. 
The number of scientific articles and patents produced by a country is a key indicator of scientific progress. Scientific output from Bolivia accounts for only $0.22 \%$ of that from all Latin America (Van Noorden, 2014), and the country's quality of life suffers from underdeveloped systems in public health and education. Unmet educational needs are compounded by resistance to modern teaching techniques (Punch, 2004), historically using rote and textbook-oriented memorization without the project-based and hands-on approaches familiar to U.S. and European students. As a result, students quickly lose interest in technical subjects (Punch, 2004). To counteract these innovation roadblocks, novel collaborations in Bolivia expose students to an engaging learning environment, via joint work by foreign and domestic scientists, empowering the next generation of technological innovators.

\section{CLUBES DE CIENCIA BOLIVIA}

With U.S. Department of State Public Diplomacy seed funding, in 2015 a small group of Harvard graduate students founded Clubes de Ciencia Bolivia (CdeCBo). The non-profit endeavor recruits U.S. and European scientists to design and execute project-based workshops in a handful of STEM topics, offered cost-free to competitively selected student applicants from across Bolivia. The goal was simple: to bring the best of laboratory science education from the world's top research universities for the first time directly to Bolivian students, and simultaneously empower local teachers to pick up the mantle after CdeCBo instructors return home. Fast forward to CdeCBo's fourth iteration in 2019, and our team of Spanish-speaking instructors from Harvard, Johns Hopkins, MIT, UCSF, and others packed the classrooms and laboratories of the Universidad Privada de Santa Cruz de la Sierra (UPSA), with 450 high school and university students. By exploiting national television and social media platforms, we had reached over half of internet-enabled Bolivian youth aged 1824 to gauge their perceptions toward life sciences, and identified educational gaps to address (Ferreira et al., 2019). The result was a set of 17 parallel courses held during summer break in January, each an intensive 5-day series of lecture-based and laboratory workshops, culminating in a student-led science fair and a publicly attended symposium. Participatory student engagement and input from local co-instructors foster a collaborative spirit.

The most popular of all courses has been Regenerative Neuroscience. In this course, students were exposed to recent advances, namely CRISPR-Cas9, gene therapy, and human-machine interfaces, as well as recent paradigmshifting discoveries such as transplantation medicine and lifelong mammalian neurogenesis (Ferreira et al., 2019). Guided literature reviews taught students to distill current understandings of neurological disorders and explore diseasemodifying therapies, and laboratory experiments enabled first-hand experience of neurophysiological principles. After lectures on neurotransmission, students recorded and manipulated neuromuscular impulses in cockroaches (Dagda et al., 2013), then safely exerted neuromuscular control over fellow students' movements through electrodes placed on the ulnar nerve in the forearm. From classroom, to lab, to science fair, the student experience went full circle-from introduction to neuroscience, to direct experimentation and presentation of knowledge and skills to their peers. Though familiar to trainees in developed nations, such methods are not typically offered in Bolivia even at the university level. Indeed, we found that our students obtained higher scores in biology tests after taking our one week-long courses than students who took semester-long college courses in Bolivian universities covering the same topics (Ferreira et al., 2019). Moreover, we have already seen CdeCBo alumni go on to pursue postgraduate programs and research internships abroad in biomedical science and medicine.

In Bolivia, the CdeCBo effect reached far beyond the classrooms. Following the program's announcement, President Evo Morales summoned a congress of over 50 Bolivian expatriate scientists back to Tiquipaya to discuss the country's scientific future for the first time (Corz, 2016). A new scholarship program launched by President Morales vowed to support 100 students of exceptional promise to enter Masters and Doctoral studies, with CdeCBo alumni counted among these distinguished awardees. In late 2018, CdeCBo held satellite workshops at the Bolivian Embassy in Washington, D.C. (Carosso et al., 2019), home of the world's largest Bolivian expatriate community. We met with Bolivia's Vice President in early 2019 to lay plans for establishing the country's first innovation district. Avenues proposed include opening diplomatic science offices in U.S. cities, akin to those of Mexico and Colombia, and establishing a ministry for science and technology, a promising step seen recently in neighboring LAC nations (Triunfol, 2007; Carosso et al., 2019). We believe these are important steps toward a diplomatic understanding between two countries with diminished formal relations.

\section{GLOBAL EMPOWERMENT THROUGH SCIENCE OUTREACH}

In a highly interconnected world, how can scientists and science agencies aid in uniting the global community? By listening to students' motivations and views toward life sciences, we stumbled on a transformative idea: scientists as non-state actors of public diplomacy (Ruffini, 2017). Our experience in CdeCBo quickly taught us that even in a diplomatically distanced nation, we ourselves could create measurable public impact and increase excitement for science (Ferreira et al., 2019). We learned that Bolivian students ask exactly the same questions we do, regarding career aspirations and how to achieve them. Simply sharing personal histories in a relaxed atmosphere often was enough to encourage students to reach out and take their own initiative, writing to faculty in the U.S. and beyond to gain research experience. In Bolivia, as anywhere else, the joy of scientific discovery was contagious.

Personal connection can shatter border walls (Rivas and Mullet, 2016). For instance, shortly after the reinstatement of diplomatic relations between the United States and Cuba in 2014, a delegation of American scientists visited their Cuban counterparts in an event jointly organized by the American Association for the Advancement of Science (AAAS) and the 
Cuban Academy of Sciences (Fink et al., 2014). This meeting led to cooperation agreements being signed in several areas, including neuroscience research and student exchange (Cohen et al., 2015). Similarly, the establishment of computer science and 3D printing clubs by Israeli and German scientists in Palestinian refugee camps has led to empowerment and integration of students with the wider population (Aal et al., 2014; Stickel et al., 2015; Yerousis et al., 2015). In Bolivia, CdeCBo students found that science is done by real people no different from them, with notions of a technocratic, self-serving scientific elite giving way to innate curiosity (Pinskey et al., 2018; Ferreira et al., 2019). It is one thing to memorize a chapter's worth of neuromuscular physiology, but catch a Bolivian cockroach and learn to control its movements through an iPhone, by surgical placement of miniaturized electrodes, and it's clear to us that the impact of learning will last. We all have teachers who rise above the rest in nourishing scientific growth, and more often than not simple factors of personal accessibility and investment are the most meaningful.

Beyond the classroom, public outreach techniques gave CdeCBo a louder voice. Targeted social media outreach and sponsored hackathons, coupled with partnerships at television networks, newspapers, and business incubators, promoted the idea of scientific research as an attainable career. Web-based platforms, such as the STEM Advocacy Initiative's Stories in Science, allowed digital scientific communities to emerge so that students from Bolivia to Bangalore to Boston can learn and work together. Effective content includes showcases of CdeCBo alumni success, whether landing awards, scholarships, or internships, giving past and prospective students a socially-supported motivation to excel academically. Profiling the work of CdeCBo instructors themselves also drove significant engagement. In short, we sought to equate the enjoyment of learning with the attention-grabbing draw of social networks and popular culture (McClain and Neeley, 2014). The powerful community-building qualities of digital media can thus be used in a meaningful way to intrinsically motivate entry into science.

\section{BRIDGING BORDERS NEAR AND FAR}

Effective STEM education strategies need not always traverse hemispheres, as successful models already exist among LAC countries. Both private and government-supported programs have been launched to retool public thinking in science. The Chilean Economic Development Agency, for instance, launched Start-Up Chile to bootstrap high-potential entrepreneurs, with $\$ 400 \mathrm{M}$ in funds to date and today ranking among the top 10 such accelerators globally and inspiring the adoption of similar structures in 50 other countries. Indeed, Start-Up Chile now supports its first Bolivian startup comprised of CdeCBo members. In Brazil, the Federal Agency for Support and Evaluation of Graduate Education (CAPES) funds 93,000 fellowships supporting STEM graduate students abroad (Rivas and Mullet, 2016). Recognizing the importance of domestically based talent, the prestigious International Brain Research Organization (IBRO) awards "Return Home" fellowships that incentivize the best young neuroscientists trained abroad to establish careers in their home country. Similarly, support from the Society for Developmental Biology, American Society for Cell Biology, University of Michigan, and others has enabled analogous workshops to reach students in Puerto Rico as well as domestically in the United States (Pinskey et al., 2018). Such efforts serve to complete a circle of sustained talent exchange, whereby developing nations can more quickly reach the forefront of global STEM, simultaneously accelerating domestic innovation and culturally enriching developed nations with fresh perspectives (Figure 1).

University-backed efforts are critical to scientific talent exchange. CdeCBo instructors stay in touch with students as mentors, reference letter providers, or simply as career counselors. Last year, a CdeCBo alumnus became the first Latin American student to win a Harvard Stem Cell Institute research fellowship. Support from Johns Hopkins University's McKusickNathans Institute of Genetic Medicine made possible the 2018 neuroscience course, and in 2019 a new partnership with IBRO, awarded through its Global Advocacy Seed Grant Initiative, expanded the workshop with new laboratory equipment. Thus, an increasing awareness of the mutually beneficial effects of diversity among student populations can be harnessed not only among populations within developed countries, but also overseas toward the inclusion of distant nations.

\section{ALIGNED INCENTIVES: DOING WELL BY DOING GOOD}

Scientific self-empowerment in developing nations produces reciprocal and exponential benefits to the global community. Domestically, increased public recognition of innovation-based improvements in public health and technology sectors will make investment in technology-driving education a sustainable business model for a wider range of public and private institutions, rather than just the wealthiest ones. As a hypothetical example, South America's rainforests house a wealth of current and future medicinal resources. The ability to identify, sustainably extract, and profit from these materials would be game-changing for a historically impoverished nation. Its government may then become less vulnerable to short-term, destructive stopgaps like deforestation. In Bolivia, engineering expertise could open access to untapped natural gas and mineral reserves. In the Atacama Desert of Northern Chile, domestic initiatives could build deep-space observatories and give Chileans academic ownership over discoveries made in their own backyard. Whether competing or collaborating with extant projects, the result will be more rapid evolution of technologies and their associated rewards. Reciprocally, developed nations greatly benefit from recruitment of foreign students. In fact, many U.S. STEM graduate programs largely depend on foreign students, some having 35-90\% international students. Moreover, scientific publications by authors of differing ethnicities receive up to $10 \%$ more citations (Freeman and Huang, 2014), and inclusion of at least one international author consistently boosts citations (Adams, 2013). 


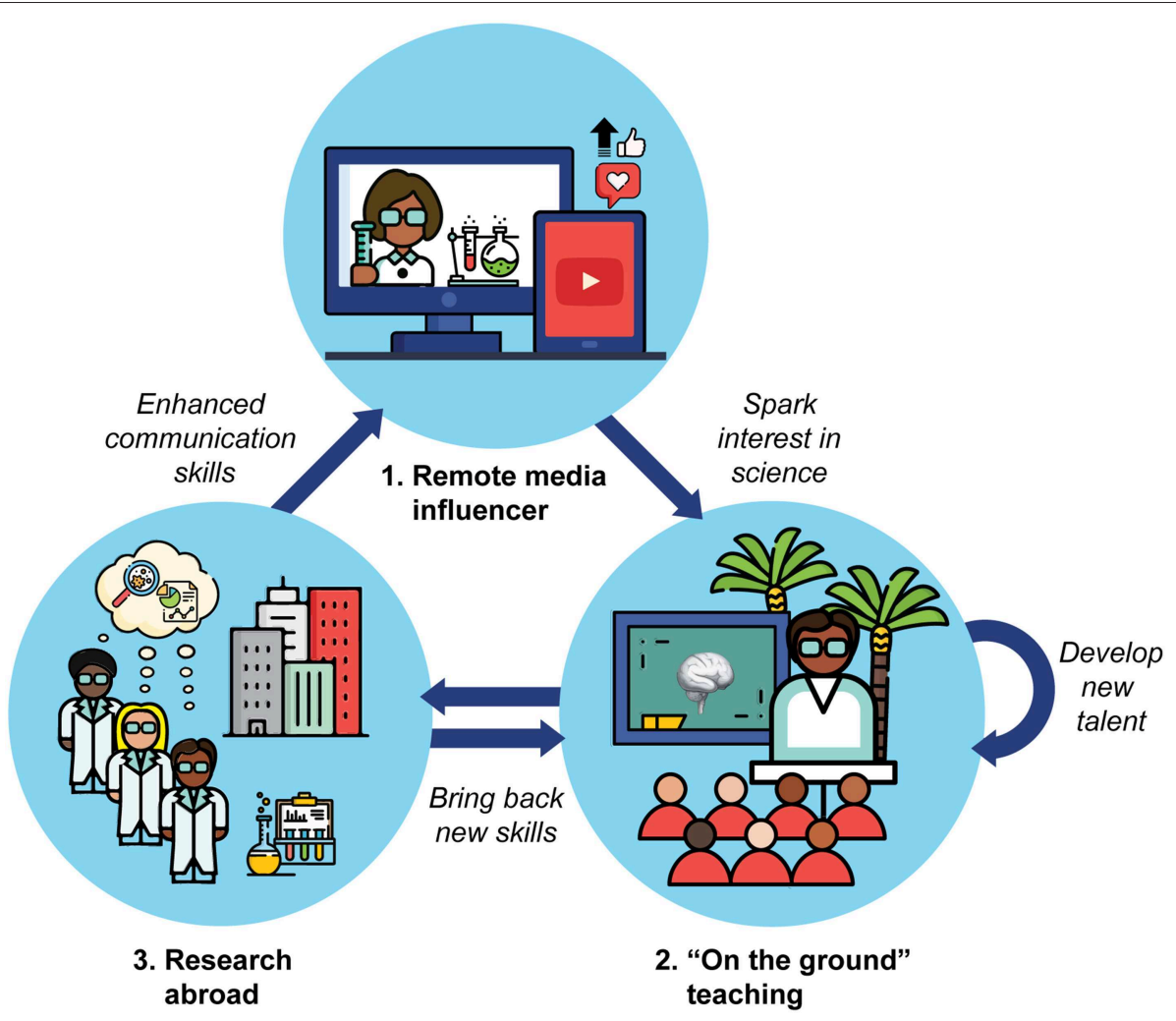

FIGURE 1 | The circle of scientific talent exchange. 1. Scientists from developed nations share scientific methods to drive engagement and aspiration among local students in developing nations. 2. "On the ground" instruction in science, technology, engineering, and mathematics (STEM) by visiting scientists from developed nations, via initiatives like Clubes de Ciencia Bolivia, galvanizes student confidence through first-hand experience and training. Co-instruction with local scientists cultivates a pool of local talent. 3. Experience of local students and alumni increases competitiveness in attaining internships and fellowships at research universities of developed nations, resulting in bilateral transfer of advanced skills and cultural perspectives. Newly trained scientists are incentivized to return home, establishing robust research infrastructure. Growth of a specialized workforce, in concert with domestic policies supporting research institutes in a developing nation, heightens national ranking in STEM. Enhanced science communication skills and social media participation further encourage local students toward STEM, inspiring a new generation of youth in developing countries to start their scientific journey. Importantly, developed nations reciprocally benefit from student exchange initiatives, as international diversity in perspectives and approaches correlates with academic productivity and success in science.

\section{A CAVEAT}

International research collaborations, particularly those by investigators from developed nations engaging in much less developed countries, present a higher degree of social responsibility. The urgency surrounding efforts to combat the 2015 Zika virus outbreak in South America exposed a number of uncomfortable realities in the scientific community. Lacking adequate resources to compete with foreign investigators, local scientists were largely forced to concede attribution over authorships, not receiving commensurate credit for publications stemming often from their own previous work (ChinchillaRodríguez et al., 2018; Machado-Silva et al., 2019). For instance, while several South American institutions collaborated in Zika virus research, all the leading institutions for Zika-related patents are based in the United States, China, and France (MachadoSilva et al., 2019), Thus, this situation resulted in so-called "helicopter" practices-foreign-backed groups conducting massive, accelerated studies culminating in high-profile publications, then returning home without following through with real-world applications that would translate intellectual findings into local community aid (Nordling, 2018). We therefore call on developed nations, and funding agencies, to foster a healthy, reasonable degree of accountability and longterm engagement between foreign labs and local communities they work in. Such measures will ultimately strengthen trust between developed and developing nations.

\section{KALEIDOSCOPIC MOSAICISM IN SCIENCE}

In the developed world, we owe much of our scientific prowess, and its innumerable ancillary benefits, to basic and applied science efforts emanating from an economically vibrant, postWorld War II technological boom. The iconic Bell Labs gave us radio astronomy, transistors, the laser, $\mathrm{C}++$, and the list goes on, in the process garnering no $<9$ Nobel prizes. Then, as today, labs like Bell's were staffed and led by a diverse group of ethnic backgrounds united in their passion for discovery. The time has come for the developed world to invest in sustainable scientific 
advancement and self-empowerment of developing nations. One cannot predict where the next breakthrough, the next paradigmshifting discovery, will come from. When entire nations are left off the train of scientific inquiry, it's not just those countries who lose, but the world at large.

\section{AUTHOR CONTRIBUTIONS}

GC, LF, and MM-R wrote this manuscript.

\section{FUNDING}

This work was supported by U.S. Department of State grants S-BL400-15-G102， S-BL400-16-IN0017， S-BL400-17-IN0055,

\section{REFERENCES}

Aal, K., Yerousis, G., Schubert, K., Hornung, D., Stickel, O., and Wulf, V. (2014). “Come_in@palestine: adapting a german computer club concept to a palestinian refugee camp," in Proceeding CABS '14 Proceedings of the 5th ACM International Conference on Collaboration Across Boundaries: Culture, Distance and Technology (Kyoto), 111-120. doi: 10.1145/2631488.2631498

Adams, J. (2013). Collaborations: the fourth age of research. Nature 497, 557-560. doi: $10.1038 / 497557 a$

Birns, L., and Sanchez, A. (2011). "From obscurity to center stage: the architectonics of bolivia's foreign policy," in Latin American Foreign Policies, eds G. L. Gardini and P. Lambert (New York, NY: Palgrave Macmillan), 103-118. doi: 10.1057/9780230118270_7

Carosso, G. A., Ferreira, L. M. R., and Mostajo-Radji, M. A. (2019). Scientists as non-state actors of public diplomacy. Nat. Hum. Behav. doi: 10.1038/s41562-019-0716-1. [Epub ahead of print].

Chinchilla-Rodríguez, Z., Miao, L., Murray, D., Robinson-García, N., Costas, R., and Sugimoto, C. R. (2018). A global comparison of scientific mobility and collaboration according to national scientific capacities. Front. Res. Metrics Analy. 3:17. doi: 10.3389/frma.2018.00017

Cohen, M. S., Hillyard, S. A., Galler, J. R., Neville, H. J., Rasenick, M. M., Reeves, A. J., et al. (2015). Opinion: advancing neuroscience interactions with Cuba Proc. Natl.Acad. Sci. U. S. A. 112, 5859-5861. doi: 10.1073/pnas.1504973112

Corz, C. (2016). Morales Pide a Científicos Bolivianos Contribuir a la Liberación Tecnológica y Científica del País. La Razon. Available online at: http://www.larazon.com/sociedad/Morales-cientificos-liberacion-tecnologica-cientifica_0_ 2413558680.html.

Dagda, R. K., Thalhauser, R. M., Dagda, R., Marzullo, T. C., and Gage, G. J. (2013). Using crickets to introduce neurophysiology to early undergraduate students. J. Undergrad. Neurosci. Educ. 12, A66-A74. Available online at: https://www. funjournal.org/wp-content/uploads/2015/09/june-12-66.pdf?x89760

Ferreira, L. M. R., Carosso, G. A., Duran, N. M., Bohorquez-Massud, S. V., VacaDiez, G., Rivera-Betancourt, L. I., et al. (2019). Effective participatory science education in a diverse Latin American population. Palgrave Commun. 5:63. doi: 10.1057/s41599-019-0275-0

Fink, G. R., Leshner, A. I., and Turekian, V. C. (2014). Science diplomacy with Cuba. Science 344:1065. doi: 10.1126/science.1256312

Freeman, R. B., and Huang, W. (2014). Collaboration: strength in diversity. Nature 513:305. doi: 10.1038/513305a

Machado-Silva, A., Guindalini, C., Fonseca, F. L., Pereira-Silva, M. V., and Fonseca, B. P. (2019). Scientific and technological contributions of Latin America and Caribbean countries to the Zika virus outbreak. BMC Public Health 19:530. doi: 10.1186/s12889-019-6842-x

McClain, C., and Neeley, L. (2014). A critical evaluation of science outreach via social media: its role and impact on scientists. F1000Res 3:300. doi: 10.12688/f1000research.5918.1 and S-BL400-18-IN0037 in Public Diplomacy, as well as the International Brain Research Organization Global Advocacy Grant, all to MM-R. GC was supported by the McKusickNathans Institute of Genetic Medicine at Johns Hopkins University School of Medicine. MM-R is currently supported by the NIH National Center for Advancing Translational Sciences, through UCSF-CTSI 5TL1TR001871-04.

\section{ACKNOWLEDGMENTS}

We would like to thank Catherine Dulac, Madeline Andrews, and Aparna Bhaduri for insightful comments on this manuscript. Pamela Toledo provided invaluable help in the design of the figure.

Nordling, L. (2018). African scientists call for more control of their continent's genomic data. Nature. doi: 10.1038/d41586-01804685-1. [Epub ahead of print].

Pinskey, J. M., Dulka, E. A., Ramos, A. I., Echevarría-Andino, M. L., Lorberbaum, D. S., Carpenter, B. S., et al. (2018). Developing Future Biologists: creating and assessing a portable short course to engage underrepresented undergraduate students in developmental biology. bioRxiv [Preprint]. doi: 10.1101/ 467092

Punch, S. (2004). The impact of primary education on school-to-work transitions for young people in rural Bolivia. Youth Soc. 36, 163-182. doi: $10.1177 / 0044118 X 04265155$

Rivas, R. M., and Mullet, S. (2016). Countervailing institutional forces that shape internationalization of science: an analysis of Brazil's Science without Borders program. Rev. Administ. Inov. 13, 12-21. doi: 10.1016/j.rai.2016. 04.001

Ruffini, P. B. (ed.). (2017). "What is science diplomacy?" in Science and Diplomacy. Science, Technology and Innovation Studies (Basel; Cham: Springer), 11-26. doi: 10.1007/978-3-319-55104-3_2

Stickel, O., Hornung, D., Aal, K., Rohde, M., and Wulf, V. (2015). “3D printing with marginalized children - an exploration in a palestinian refugee camp," in ECSCW 2015: Proceedings of the 14th European Conference on Computer Supported Cooperative Work, eds N. Boulus-Rødje, G. Ellingsen, T. Bratteteig, M. Aanestad, and P. Bjørn (Oslo; Cham: Springer).

Triunfol, M. L. (2007). Latin American Science Moves into the Spotlight. Cell 131, 1213-1216. doi: 10.1016/j.cell.2007. 12.008

Van Noorden, R. (2014). The impact gap: South America by the numbers. Nature 510, 202-203 doi: 10.1038/510202a

Yerousis, G., Aal, K., von Rekowski, T., Randall, D. W., Rohde, M., and Wulf, V. (2015). "Computer-enabled project spaces: connecting with palestinian refugees across camp boundaries," in Proceeding CHI '15 Proceedings of the 33rd Annual ACM Conference on Human Factors in Computing Systems (Seoul), 3749-3758. doi: 10.1145/2702123.27 02283

Conflict of Interest Statement: The authors declare that the research was conducted in the absence of any commercial or financial relationships that could be construed as a potential conflict of interest.

Copyright (C) 2019 Carosso, Ferreira and Mostajo-Radji. This is an open-access article distributed under the terms of the Creative Commons Attribution License (CC BY). The use, distribution or reproduction in other forums is permitted, provided the original author(s) and the copyright owner(s) are credited and that the original publication in this journal is cited, in accordance with accepted academic practice. No use, distribution or reproduction is permitted which does not comply with these terms. 